\title{
Are Hook Plate Complications Inevitable?
}

\author{
Hyun Seok Song \\ Department of Orthopedic Surgery, St. Paul's Hospital, College of Medicine, The Catholic University of Korea, Seoul, Korea
}

The clavicle hook plate is employed for treating acromioclavicular (AC) and coracoclavicular (CC) ligament injuries, or distal clavicle fractures with comminution. The hook plate does not penetrate the articular cartilage of the AC joint and demonstrates a firm resistance to upward displacement of the distal clavicle." Several studies report promising results using the hook plate for displaced lateral clavicle fracture ${ }^{2-5)}$ and for $\mathrm{AC}$ and CC ligament injuries. $^{6,7)}$

However, several drawbacks are associated with the hook plate. Location of the hook in the subacromial space makes this area more crowded. Additionally, the hook plate can induce subacromial impingement, ${ }^{8)}$ resulting in discomfort from the hardware. Furthermore, some cases have reported torn rotator cuffs. $^{8)}$

Secondly, placing the hook under the acromion may cause acromial erosion. Sim et al. ${ }^{9)}$ reported erosion in $62 \%$ of their cases, whereas Kim et al. ${ }^{10)}$ reported the incidence in all cases. Oh et al. ${ }^{11)}$ observed subacromial erosion in AC joint dislocation and distal clavicle fractures, with significantly greater frequency in the group of distal clavicle fracture $(66.7 \%)$ than in AC joint dislocation (56.4\%). However, in the study by Oh et al.. ${ }^{11)}$ the hook plate was removed earlier in the AC joint dislocation group (mean, 5.31 months) than in the distal clavicle fracture group (mean, 9.65 months). The difference in the duration from surgery to removal could affect the incidence or severity of the complication arising due to hook plate.

Other case studies have reported occurrence of acromion fractures at the weakened location, ${ }^{12-14)}$ with one study reporting a hook cutting through the acromion. ${ }^{15)}$

The causes resulting in these complications need to be analyzed to prevent future difficulties. Some biomechanical studies with hook plate have been performed. Lin et al. ${ }^{8)}$ described the preservation of rotation of the AC joint during shoulder abduc- tion and flexion after hook plate; however, they did not provide any objective data. Kim et al. ${ }^{10)}$ analyzed the AC joint motion using a three-dimensional (3D) reconstruction model of 3D computed tomography images. In the normal joint, the axis of rotation of the $\mathrm{AC}$ joint is assumed at the center, whereas in a hook plate the hook is located posterior to the center of the AC joint. This causes an inconsistency between the center of rotation of the distal clavicle and the rotation axis of the plate, thereby resulting in erosion of the acromion or limitation of motion. This hook also blocks the sagittal rotation of the AC joint inhibiting the posterior tilt of the acromion, resulting in decreased internal rotation of the distal clavicle. ${ }^{10)}$

Most authors recommend removal of the hook plate to decrease incidence of complications. Lin et al. ${ }^{8)}$ advocated removal of the hook plate as soon as the bony union is achieved. Although complications of the hook plate are inevitable, all complications resolved after removal of the hook plate. ${ }^{14)}$ However, earlier removal of the hook plate only resulted in decreased complications.

\section{References}

1. Nüchtern JV, Sellenschloh K, Bishop N, et al. Biomechanical evaluation of 3 stabilization methods on acromioclavicular joint dislocations. Am J Sports Med. 2013;41(6):1387-94.

2. Good DW, Lui DF, Leonard M, Morris S, McElwain JP. Clavicle hook plate fixation for displaced lateral-third clavicle fractures (Neer type II): a functional outcome study. J Shoulder Elbow Surg. 2012;21(8):1045-8.

3. Kim KC, Shin HD, Cha SM, Jeon YS. Hook plate fixation for unstable distal clavicle fractures: a prospective study. Clin Shoulder Elbow. 2011;14(1):6-12.

4. Tan HL, Zhao JK, Qian C, Shi Y, Zhou Q. Clinical re-

\section{Correspondence to: Hyun Seok Song}

Department of Orthopedic Surgery, St. Paul's Hospital, College of Medicine, The Catholic University of Korea, 180 Wangsan-ro, Dongdaemungu, Seoul 02559, Korea

Tel: +82-2-958-2159, Fax: +82-2-965-1456, E-mail: hssongmd@yahoo.com, ORCID: https://orcid.org/0000-0002-7844-2293

Editorial does not need an IRB approval.

Financial support: None. Conflict of interests: None. 
sults of treatment using a clavicular hook plate versus a Tplate in Neer type II distal clavicle fractures. Orthopedics. 2012;35(8):e1191-7.

5. Tiren D, van Bemmel AJ, Swank DJ, van der Linden FM. Hook plate fixation of acute displaced lateral clavicle fractures: midterm results and a brief literature overview. J Orthop Surg Res. 2012;7:2.

6. Jensen G, Katthagen JC, Alvarado LE, Lill H, Voigt C. Has the arthroscopically assisted reduction of acute AC joint separations with the double tight-rope technique advantages over the clavicular hook plate fixation? Knee Surg Sports Traumatol Arthrosc. 2014;22(2):422-30.

7. von Heideken J, Boström Windhamre H, Une-Larsson V, Ekelund A. Acute surgical treatment of acromioclavicular dislocation type $\mathrm{V}$ with a hook plate: superiority to late reconstruction. J Shoulder Elbow Surg. 2013;22(1):9-17.

8. Lin HY, Wong PK, Ho WP, Chuang TY, Liao YS, Wong CC. Clavicular hook plate may induce subacromial shoulder impingement and rotator cuff lesion: dynamic sonographic evaluation. J Orthop Surg Res. 2014;9:6.

9. Sim E, Schwarz N, Höcker K, Berzlanovich A. Repair of complete acromioclavicular separations using the acromioclavicular-hook plate. Clin Orthop Relat Res. 1995;(314):134-42.
10. Kim YS, Yoo YS, Jang SW, Nair AV, Jin H, Song HS. In vivo analysis of acromioclavicular joint motion after hook plate fixation using three-dimensional computed tomography. J Shoulder Elbow Surg. 2015;24(7):1106-11.

11. Oh JH, Min S, Jung JW, et al. Clinical and radiological results of hook plate fixation in acute acromioclavicular joint dislocations and distal clavicle fractures. Clin Shoulder Elbow. 2018;21(2):95-100.

12. Chiang CL, Yang SW, Tsai MY, Kuen-Huang Chen C. Acromion osteolysis and fracture after hook plate fixation for acromioclavicular joint dislocation: a case report. J Shoulder Elbow Surg. 2010;19(4):e13-5.

13. Kashii M, Inui H, Yamamoto K. Surgical treatment of distal clavicle fractures using the clavicular hook plate. Clin Orthop Relat Res. 2006;447:158-64.

14. Kienast B, Thietje R, Queitsch C, Gille J, Schulz AP, Meiners J. Mid-term results after operative treatment of rockwood grade III-V acromioclavicular joint dislocations with an AC-hookplate. Eur J Med Res. 2011;16(2):52-6.

15. Hoffler CE, Karas SG. Transacromial erosion of a locked subacromial hook plate: case report and review of literature. J Shoulder Elbow Surg. 2010;19(3):e12-5. 